Saudi Journal of Biomedical Research

Abbreviated Key Title: Saudi J Biomed Res ISSN 2518-3214 (Print) IISSN 2518-3222 (Online)

Scholars Middle East Publishers, Dubai, United Arab Emirates

Journal homepage: https://saudijournals.com/sjbr

Original Research Article

\title{
MNAD Hypothesis Based Protocol Proposed for Treatment of COVID.19: Assessment of Minocycline, N. acetylcysteine, Aspirin \& vitamin D (MNad) Theory for treatment of COVID.19 Adults Patients
}

Mosab Nouraldein Mohammed Hamad, BSC (honors), MSC ${ }^{1,2^{*}}$, Mohammed Abdelgafoor Abdelgadir Salih, $\mathrm{MD}^{2}$, Mohammed Omer Mohammed Hussein, BSC, MSC, PGA ${ }^{2}$, Sufian Khalid Mohammed Nor ${ }^{3}$, Haifaa Mohamed Saeed $\mathrm{MD}^{2}$, Fatima Omer Mohamed BSC ${ }^{2}$

${ }^{1}$ Lecturer of Medical Parasitology, Elsheikh Abdallah Elbadri University, Berber, Sudan

${ }^{2}$ Research unit, Banoon Fertility Center, Khartoum, Sudan

${ }^{3}$ Professor of Internal Medicine, Nile Valley University, Atbara, Sudan

\author{
DOI: $10.36348 /$ sjbr.2020.v05i11.007 \\ | Received: 01.11.2020 | Accepted: 09.11.2020 | Published: 23.11.2020 \\ *Corresponding author: Mosab Nouraldein Mohammed Hamad
}

\section{Abstract}

COVID.19 Pandemic is a real disaster facing the globe, and up to date its uncontrollable, due to absence of data about the real mechanism upon which this virus overcome immune system and induce lethal symptoms certainly among aged and those with low-level of immunity. MNAD hypothesis based protocol aimed to measure validity of combination Minocycline as antibiotic, N. acetyl cysteine as antioxidant, aspirin as anticoagulant and vitamin D as immune regulator to treat COVID.19 infection. This protocol opened and implemented by any institutions or health authority after permission of the corresponding author of it.

Keywords: Minocycline, N.acetyl cysteine, Aspirin, Vitamin D, COVID.19.

Copyright $\odot$ (2020 The Author(s): This is an open-access article distributed under the terms of the Creative Commons Attribution 4.0 International License (CC BY-NC 4.0) which permits unrestricted use, distribution, and reproduction in any medium for non-commercial use provided the original author and source are credited.

\section{INTRODUCTION}

On 31 December 2019, the World Health Organization (WHO) informed of cases of pneumonia of unknown cause in Wuhan City, Hubei Province, China. Subsequent virological testing showed that a novel $\mathrm{CoV}$ detected in these patients. The symptomatology of these patients included fever, malaise, dry cough, and dyspnea [1]. In addition, headache, dizziness, generalized weakness, vomiting, diarrheas [2], muscle pain, confusion, headache, sore throat, rhinorrhea, chest pains observed [3]. Based on the cells that are likely infected, COVID-19 divided into three phases that correspond to different clinical stages of the disease.

Stage 1: Asymptomatic state (first 1-2 days of infection):

The inhaled virus SARS-CoV-2 likely binds to epithelial cells in the nasal cavity and starts replicating.

Stage 2: Upper airway and conducting airway response (next few days):

The virus propagates and migrates down the respiratory tract along the conducting airways, and a more vigorous innate immune response is triggered.
Stage 3: Hypoxia, ground glass infiltrates, and progression to ARDS:

Unfortunately, about $20 \%$ of the infected patients will progress to stage 3 disease and will develop pulmonary infiltrates and some of these will develop very severe disease. Initial estimates of the fatality rate are around $2 \%$, but this varies markedly with age [4].

Critical complications observed in some patients such as shock, encephalopathy, myocardial injury, heart failure, coagulation dysfunction and acute kidney injury [2].

According to MOA Duplication \& Deletion Theory" The pathogenesis of COVID-19 attributed to its ability to induce 4p15.1-pter duplication and a 4q35.1-qter deletion in recombinant of chromosome-4 pericentric inversion through gene duplication method named retrotransposition, duplication lead to mental defects, while deletion lead to cardiac defects due to loss of ArgBP2 and PDLIM3 genes, whom are necessary for normal cardiac muscle functions" [5], supported by study reported that A locus for bipolar 
affective disorder on chromosome $4 \mathrm{p}$ [6] we propose that bipolar depression is the mental disorder resulted from mutation induced by SARS-COV-2, that lead to life threatening complications.

Bipolar depression patients have increased risk of many general-medical disorders, including vascular conditions, with increased morbidity, disability and diminished longevity. In addition, obesity, diabetes, migraine, and some infectious diseases are more prevalent among $\mathrm{BD}$ patients. With $\mathrm{BD}$, risk of myocardial infarction was $37 \%$ greater, stroke $60 \%$, and congestive heart failure nearly $230 \%$ greater than in age-matched general populations. Mediating factors include obesity, inactivity, diabetes or metabolic syndrome, and increased inflammatory factors-all with increased prevalence among BD patients [7]. Bipolar disorder in youth associated with increased levels of vitamin D-binding protein [8] and that means low levels of vitamin D. Also increased risk for pulmonary embolism in patients with bipolar disorder was observed [9]. Catatonia which is one of the bipolar spectrum disorders can lead to pneumonia, obstructive nephropathy, azotemia, deep vein thrombosis (DVT), and ultimately pulmonary embolism (PE) [10]. MNa theory stated that Minocycline, N.acetylcysteine and Aspirin are capable to treat COVID.19 [11], and addition of vitamin D supplements improve the outcomes [12].

\section{MNad hypothesis therapeutic components Minocycline}

Minocycline (7-dimethylamino-6-dimethyl-6deoxytetracycline) is a second-generation, semisynthetic tetracycline analogue that has been used for over 30 years. Minocycline shows a better pharmacokinetic profile than the first-generation tetracyclines when used orally, being rapidly and completely absorbed, even in elderly populations, with a longer half-life and excellent tissue penetration, and an almost complete bioavailability. In addition to, it is a highly lipophilic molecule that can easily pass through the blood-brain barrier, thus promoting its accumulation in cells of the CSF and CNS and enabling its use in the treatment of many CNS diseases. Moreover, minocycline has a good safety record when used chronically. Long-term treatment with minocycline at dosages of up to $200 \mathrm{mg} / \mathrm{day}$, the highest dosage recommended by the US FDA, is generally safe and well-tolerated in humans. Minocycline's known and most common side effects, including nausea, vertigo and mild dizziness, occur mainly early after its administration and disappear shortly following therapy discontinuation. Moreover, the growing interest in minocycline has led to evaluations of its therapeutic efficacy in many other experimental disease models, such as inflammatory bowel disease, diabetes, cardiac ischemia and human immunodeficiency virus (HIV) infection [13].Also it used as treatment for Lung Scarring in Patients with
Idiopathic Pulmonary Fibrosis [14], minocycline and aspirin efficacious adjunctive therapies for the treatment of bipolar depression [15].

\section{$N$-acetylcysteine}

$\mathrm{N}$-acetylcysteine (NAC) used as an antioxidant precursor to glutathione ( $\gamma$-glutamylcysteinylglycine; $\mathrm{GSH}$ ) to treat of paracetamol overdose for more than 30years.1 As more understood about the actions of NAC, the clinical applications have also broadened. Nacetylcysteine is now widely used as a mucolytic and to treat of HIV, and it has reported efficacy in chronic obstructive pulmonary disease and contrast-induced nephropathy [16]. It has been explored for psychiatric disorders for some time given its antioxidant and antiinflammatory properties.

It is well-tolerated with few and often mild adverse events. It hypothesized to decrease symptoms of depression at least in part due to its antioxidant properties [17]. Also it helps With Detoxification to prevent or Diminish Kidney and Liver Damage, Improve Psychiatric Disorders, Relieve Symptoms of Respiratory Conditions, Boosts Brain Health by Regulating Glutamate and Replenishing Glutathione, Improve Fertility in Both Men and Women, Stabilize Blood Sugar by Decreasing Inflammation in Fat Cells, Reduce Heart Disease Risk by Preventing Oxidative Damage, Improve Immune Function [18], and have potent thrombolytic effect on Arterial Thrombi [19].

\section{Aspirin}

It is an orally administered non-steroidal antiinflammatory agent. Acetylsalicylic acid binds to and acetylates serine residues in cyclooxygenases, resulting in decreased synthesis of prostaglandin, platelet aggregation, and inflammation. This agent exhibits analgesic, antipyretic, and anticoagulant properties [20]. Also low dose aspirin and minocycline as adjunctive treatments for bipolar depression [21].

\section{Vitamin D supplements}

Vitamin D is a necessary nutrient that obtained from the diet when sufficient quantities cannot be synthesized. Vitamin $\mathrm{D}_{3}$ is primarily produced following incidental skin exposure to ultraviolet $\mathrm{B}$ irradiation, with very little derived from dietary sources. Cutaneous production absent or dramatically reduced due to skin coloration and sunblock use. Melanin in the skin of Africans or African-Americans blocks nearly 99\% of vitamin D production. Indoor activities, pollution, time of day, increasing age, latitude, and seasonal changes all affect cutaneous vitamin D production [22].

There is no identified protocol to treat COVID.19 crisis despite of it is global spread and life threatening symptoms, just few promising clinical trials appear from time to time. It provides protective effect of vitamin D include several bone diseases, muscle weakness. 
A study in England found birth seasonality related to later diagnosis of bipolar disorder, strongly suggesting that the risk of bipolar disorder reduced through enough vitamin D intake during pregnancy [23]. Vitamin D and the omega-3 fatty acids control serotonin synthesis and action, part 2: relevance for ADHD, bipolar disorder, schizophrenia, and impulsive behavior [24]. Vitamin D deficiency is prevalent in adults with bipolar disorder [25], Patients in acute manic episode had much lower vitamin D serum concentrations [26], and Vitamin D is also involved in glycaemic control, lipid metabolism, insulin secretion, and sensitivity, explaining the association between vitamin D deficiency and metabolic syndrome. Vitamin $\mathrm{D}$ deficit associated in some studies with the number of affected coronary arteries, post-infarction complications, inflammatory cytokines and cardiac remodeling in patients with myocardial infarction, direct electromechanical effects and inflammation in atrial-fibrillation, and neuroprotective effects in stroke, then compensation through supplement is very necessary to vitamin D deficient people [27].

No drug interactions detected between minocycline, N.acetylcysteine, aspirin and vitamin D [28].

Coronavirus COVID-19 pandemic is the defining global health crisis of our time and the greatest challenge we have faced since World War Two. Since its emergence in Asia late last year, the virus has spread to other parts of the world including Sudan, up to date world health organization and scientific community failed to introduce familiar therapeutic protocol for this health crisis, as we are suffering from it, we intend to enter the war against SARS-COV.2 , through implementation of new therapeutic protocol.

\section{OBJECTIVES}

\section{General objectives}

To asses Minocycline, N.acetylcysteine, Aspirin \& vitamin D (MNad) Theory for treatment of SARS-COV.2 adults Patients

\section{Specific objectives}

- To measure the response to MNad theory according to severity of symptoms.

- To estimate the duration needed for MNad therapeutic method to relive clinical features.

\section{MATERIAL AND METHOD}

Study design: randomized clinical trial (RCT)

Study setting: COVID.19 Patients Isolation center.

Study duration: 2 months

Study population: Confirmed SARS.COV.2 patients.
Sample size: 292 patients, 146 will exposed to MNad therapeutic protocol and equal number of the participants exposed to placebo.

Participants divided into three phases:

Phase 1: 20 participants, 10 received MNad therapies and 10 received placebo.

(week1+week2).

Phase 2: 100 participants, 50 received MNad therapies and 50 received placebo.

(week4+week5).

Phase 3: 172 participants, 86 received MNad therapies and 86 received placebo.

(week7+week8).

Formula of calculating sample size is $\mathrm{n}=\left[\left(\mathrm{Z}_{\alpha / 2}+\mathrm{Z}_{\beta}\right)^{2} \times\{(\mathrm{p} 1(1-\mathrm{p} 1)+(\mathrm{p} 2(1-\mathrm{p} 2))\}] /(\mathrm{p} 1-\right.$ p2) ${ }^{2}$ [29].

Where:

$\mathrm{n}=$ sample size required in each group,

$\mathrm{p} 1=$ proportion of subject cured by Drug $\mathrm{A}=0.50$,

p2 $=$ proportion of subject cured by Placebo $=0.34$,

$\mathrm{P} 1-\mathrm{p} 2=$ clinically significant difference $=0.16$

$\mathrm{Z}_{\alpha / 2}$ : This depends on level of significance, for $5 \%$ this is 1.96

$\mathrm{Z}_{\beta}$ : This depends on power, for $80 \%$ this is 0.85 .

Based on above formula the sample size required per group is 146 . Hence total sample size required is 292 .

A sample size of 292 participants, 146 in each arm, is enough to detect a clinically important difference of $16 \%$ between groups in curing COVID.19 using a two-tailed z-test of proportions between two groups with $80 \%$ power and a $5 \%$ level of significance. This $16 \%$ difference represents a $50 \%$ cure rate using MNad therapeutic portocol and $34 \%$ cure rate using placebo.

\section{Inclusion criteria}

18 years old and above

\section{Exclusion criteria}

Smoker, snuff user, alcoholic, addict, hepatic and renal patients, patients with ulcers or bleeding disorders, pregnant, nursing mother, used another drug (certainly anti-acids \& birth control pills), during the study period with exception of diabetic and asthmatic drugs.

\section{Method}

Patients will recommend stop smoking, snuff chewing, and consumption of caffeine containing products (tea, coffee, soft drinks) and avoid eating of dairy products during the study period; meals will be under supervision of dietary specialist, therapeutic model and accompanied clinical and other investigations will monitored by medical team ( physicians, medical officers, nurses and lab technologist ). 


\section{Pre-Treatment investigations}

- COVID.19 PCR

- Blood pressure

- Body temperature

- Serum troponin
- $\quad$ Complete blood count (CBC)

- $\quad$ Random blood glucose (RBG)

- $\quad$ C. reactive protein (CRP).

- Urine general

Medications administered according to the table mentioned below:

Table-1: MNad therapeutic protocol to COVID.19 adult patients

\begin{tabular}{|l|l|l|l|l|}
\hline Days & Minocycline & N.acetylcysteine & Vitamin D & Aspirin \\
\hline Day 1 & $200 \mathrm{mg} /$ day $($ once) & $400 \mathrm{mg} \backslash 8 \mathrm{hrs}$ & $1000 I U / d a y$ & $100 \mathrm{mg} /$ day \\
\hline Day 2 & $100 \mathrm{mg} / 12 \mathrm{hrs}$ & $400 \mathrm{mg} \backslash 8 \mathrm{hrs}$ & $1000 I U / d a y$ & $100 \mathrm{mg} /$ day \\
\hline Day 3 & $100 \mathrm{mg} / 12 \mathrm{hrs}$ & $400 \mathrm{mg} \backslash 8 \mathrm{hrs}$ & $1000 I U / d a y$ & $100 \mathrm{mg} /$ day \\
\hline Day 4 & $100 \mathrm{mg} / 12 \mathrm{hrs}$ & $400 \mathrm{mg} \backslash 8 \mathrm{hrs}$ & $1000 I U / d a y$ & $100 \mathrm{mg} /$ day \\
\hline Day 5 & $100 \mathrm{mg} / 12 \mathrm{hrs}$ & $400 \mathrm{mg} \backslash 8 \mathrm{hrs}$ & $1000 I U / d a y$ & $100 \mathrm{mg} /$ day \\
\hline Day 6 & $100 \mathrm{mg} / 12 \mathrm{hrs}$ & $400 \mathrm{mg} \backslash 8 \mathrm{hrs}$ & $1000 I U / d a y$ & $100 \mathrm{mg} /$ day \\
\hline Day 7 & $100 \mathrm{mg} / 12 \mathrm{hrs}$ & $400 \mathrm{mg} \backslash 8 \mathrm{hrs}$ & $1000 I U / d a y$ & $100 \mathrm{mg} /$ day \\
\hline Day 8 & $100 \mathrm{mg} / 12 \mathrm{hrs}$ & $400 \mathrm{mg} \backslash 8 \mathrm{hrs}$ & $1000 I U / d a y$ & $100 \mathrm{mg} /$ day \\
\hline Day 9 & $100 \mathrm{mg} / 12 \mathrm{hrs}$ & $400 \mathrm{mg} \backslash 8 \mathrm{hrs}$ & $1000 I U / d a y$ & $100 \mathrm{mg} /$ day \\
\hline Day 10 & $100 \mathrm{mg} / 12 \mathrm{hrs}$ & $400 \mathrm{mg} \backslash 8 \mathrm{hrs}$ & $1000 I U / d a y$ & $100 \mathrm{mg} /$ day \\
\hline Day 11 & & $400 \mathrm{mg} \backslash 8 \mathrm{hrs}$ & $1000 I U / d a y$ & $100 \mathrm{mg} /$ day \\
\hline Day 12 & & $400 \mathrm{mg} \backslash 8 \mathrm{hrs}$ & $1000 I U / d a y$ & $100 \mathrm{mg} /$ day \\
\hline Day 13 & & $400 \mathrm{mg} \backslash 8 \mathrm{hrs}$ & $1000 I U / d a y$ & $100 \mathrm{mg} /$ day \\
\hline Day 14 & & $400 \mathrm{mg} \backslash 8 \mathrm{hrs}$ & $1000 I U / d a y$ & $100 \mathrm{mg} /$ day \\
\hline
\end{tabular}

\section{NOTES}

Aspirin (100-300mg) will be used upon need to relieve headache episode.

Minocycline used with empty stomach \& Lay down after 10 minutes of ingesting it.

$N$-acetylcysteine after 2 hours of Minocycline.

Vitamin D after 3 hours of Minocycline dose (Morning). Aspirin after 3 hours of Minocycline( Night).

\section{Post-Treatment investigations}

\section{- SARS-COV.2 PCR}

- Blood pressure( Before each dose )

- Serum troponin

- Complete blood count (CBC) ( after completion)

- $\quad$ Random blood glucose (RBG) ( Day 1( morning\& night),Day 3, Day 5,after completion )

- C. reactive protein (CRP) ( Day 2, Day 5, Day 14)

- Urine general (after completion).

Blood glucose of diabetic patients followed up twice / day after one hour of minocycline administration, blood pressure checked before administration of doses. It's allowable to the physicians whom will follow the therapeutic plan to do required interventions according to situation of patient (e.g rehydration, etc) each non-MNad medication administered recorded.

\section{Ethical approval}

Initial consent obtained from therapeutic protocol committee; ministry of health, followed by patient or his/family consent, all participants will be informed about goals of the study.

\section{Data collection}

Data collected through well-constructed questionnaire.

\section{Statistical analysis}

Data analyzed by social statistical package (SPSS), IBM Statistic, version (2015).

Funding

Seeking for fund or collaborators

\section{REFERENCES}

1. Chan, J. F. W., Kok, K. H., Zhu, Z., Chu, H., To, K. K. W., Yuan, S., \& Yuen, K. Y. (2020). Genomic characterization of the 2019 novel human-pathogenic coronavirus isolated from a patient with atypical pneumonia after visiting Wuhan. Emerging microbes \& infections, 9(1), 221-236.

2. Yuki, K., Fujiogi, M., \& Koutsogiannaki, S. (2020). COVID-19 pathophysiology: A review. Clinical immunology, 108427.

3. Tian, S., Xiong, Y., Liu, H., Niu, L., Guo, J., Liao, M., \& Xiao, S. Y. (2020). Pathological study of the 2019 novel coronavirus disease (COVID-19) through postmortem core biopsies. Modern Pathology, 1-8.

4. Mason, R. J. (2020). Pathogenesis of COVID-19 from a cell biology perspective. 
5. Hamad, M. N. M. MOA Duplication \& Deletion Theory: COVID-19 Pathogenesis Mechanism: Gene Duplication, Retrotransposition, 4p15. 1-pter Duplication and a 4q35. 1-qter Deletion in a Recombinant of Chromosome 4 Pericentric Inversion.

6. Blackwood, D. H., He, L., Morris, S. W., McLean, A., Whitton, C., Thomson, M., ... \& Shibasaki, Y. (1996). A locus for bipolar affective disorder on chromosome 4p. Nature genetics, 12(4), 427-430.

7. Baldessarini, R. J., Vázquez, G. H., \& Tondo, L. (2020). Bipolar depression: a major unsolved challenge. International journal of bipolar disorders, 8(1), 1.

8. Petrov, B., Aldoori, A., James, C., Yang, K., Algorta, G. P., Lee, A., ... \& Samogyi, A. (2018). Bipolar disorder in youth is associated with increased levels of vitamin D-binding protein. Translational psychiatry, 8(1), 1-10.

9. Strudsholm, U., Johannessen, L., Foldager, L., \& Munk- Jørgensen, P. (2005). Increased risk for pulmonary embolism in patients with bipolar disorder. Bipolar disorders, 7(1), 77-81.

10. Ignatowski, M., Sidhu, S., \& Rueve, M. (2007). Pulmonary embolism as a complication of major depressive disorder with catatonic features: a case report. Psychiatry (Edgmont), 4(6), 51.

11. Hamad, M. N. M. MNa Theory: Triple Therapy to COVID-19: Minocycline, N-acetylcysteine and Aspirin.

12. Hamad, M. N. M. Vitamin D Supplements Improve Efficacy of Minocycline, N-Acetylcysteine and Aspirin Triple Therapy to COVID-19 Infection.

13. Garrido- Mesa, N., Zarzuelo, A., \& Gálvez, J. (2013). Minocycline: far beyond an antibiotic. British journal of pharmacology, 169(2), 337-352.

14. Eric, K. Minocycline Therapy for Lung Scarring in Patients with Idiopathic Pulmonary Fibrosis - a Pilot Study, https://clinicaltrials.gov/ct2/show/NCT00203697.

15. Savitz, J. B., Teague, T. K., Misaki, M., Macaluso, M., Wurfel, B. E., Meyer, M., ... \& Preskorn, S. H. (2018). Treatment of bipolar depression with minocycline and/or aspirin: an adaptive, $2 \times 2$ double-blind, randomized, placebo-controlled, phase IIA clinical trial. Translational psychiatry, 8(1), 1-11.

16. Dean, O., Giorlando, F., \& Berk, M. (2011). Nacetylcysteine in psychiatry: current therapeutic evidence and potential mechanisms of action. Journal of psychiatry \& neuroscience: $J P N, 36(2), 78$.

17. Ellegaard, P. K., Licht, R. W., Poulsen, H. E., Nielsen, R. E., Berk, M., Dean, O. M., ... \& Nielsen, C. T. (2018). Add-on treatment with N- acetylcysteine for bipolar depression: a 24-week randomized double-blind parallel group placebocontrolled multicentre trial (NACOS-study protocol). International journal of bipolar disorders, 6(1), 11.

18. Top 9 Benefits of NAC (N-Acetyl Cysteine). (2018). Medically reviewed by: Amy Goodson, September, 26 , https://www.healthline.com/nutrition/nac-benefits..

19. Martinez de Lizarrondo, S., Gakuba, C., Herbig, B. A., Repessé, Y., Ali, C., Denis, C. V., ... \& Gauberti, M. (2017). Potent thrombolytic effect of $\mathrm{N}$-acetylcysteine on arterial thrombi. Circulation, 136(7), 646-660.

20. National Center for Biotechnology Information. (2020). PubChem Database. Aspirin, CID $=2244$, https://pubchem.ncbi.nlm.nih.gov/compound/Aspir in (accessed on May 3, 2020).

21. Savitz, J. B., Teague, T. K., Misaki, M., Macaluso, M., Wurfel, B. E., Meyer, M., ... \& Preskorn, S. H. (2018). Treatment of bipolar depression with minocycline and/or aspirin: an adaptive, $2 \times 2$ double-blind, randomized, placebo-controlled, phase IIA clinical trial. Translational psychiatry, 8(1), 1-11.

22. Shuler, F. D., Wingate, M. K., Moore, G. H., \& Giangarra, C. (2012). Sports health benefits of vitamin D. Sports health, 4(6), 496-501.

23. Grant, W. B., \& Holick, M. F. (2005). Benefits and requirements of vitamin D for optimal health: a review. Altern Med Rev, 10(2), 94-111.

24. Patrick, R. P., \& Ames, B. N. (2015). Vitamin D and the omega- 3 fatty acids control serotonin synthesis and action, part 2: Relevance for ADHD, bipolar disorder, schizophrenia, and impulsive behavior. The FASEB Journal, 29(6), 2207-2222.

25. Boerman, R., Cohen, D., Schulte, P. F., \& Nugter, A. (2016). Prevalence of vitamin D deficiency in adult outpatients with bipolar disorder or schizophrenia. Journal of clinical psychopharmacology, 36(6), 588-592.

26. Altunsoy, N., Yüksel, R. N., Cingi Yirun, M., Kılıçarslan, A., \& Aydemir, Ç. (2018). Exploring the relationship between vitamin $\mathrm{D}$ and mania: correlations between serum vitamin D levels and disease activity. Nordic Journal of Psychiatry, 72(3), 221-225.

27. Mozos, I., \& Marginean, O. (2015). Links between vitamin D deficiency and cardiovascular diseases. BioMed research international, 2015.

28. Drug InteractionChecker https://reference.medscape.com/druginteractionchecker.

29. Sakpal, T.V. (2010). Sample size estimation in clinical trial. Perspect Clin Res. Apr; 1(2):67-9. 
Assessment of Minocycline, N.acetylcysteine, Aspirin \& vitamin D (MNad) Theory for treatment of SARS-COV.2 Adults Patients

Date: Patient NO

Name: Gender. Mitral status:

Address: Age: Gender....

Renal disease:

Liver disease: Nursing mother:

Pregnant : Addict:

Alcoholic: Drugs used:

Chronic diseases

Anti-acids. birth control pills:

Smoker: Snuff chewer.

Family history of psychotic diseases:...........family history of cardiac diseases: ulcers:......bleeding disorders.

Pre. Treatment examinations:

SARS-COV-2 PCR: ….......Blood pressure. serum troponin ..............Body temperature:..........

$R B G$ :..................CRP: $C B C$ :

Urine general:

Post .treatment examination:

SARS-COV-2 PCR:............Blood pressure: serum troponin Body

temperature: $C R P$ :

$C B C$ :

Urine general: non-MNad medication:

Patient consent: participant

I am informed about the goals of this study and I am voluntarily and optionally accept to involve in it, researchers are not responsible for any un-excepted complications

Participant signature:

Investigator signature

Date: 